\title{
Assessment of Postural Stability in Children with Developmental Coordination Disorder- Indian Context
}

\author{
Ganapathy Sankar $\mathbf{U}^{1}$ and Monisha $\mathbf{R}^{2 *}$ \\ ${ }^{1}$ Professor, SRM College of Occupational Therapy, India \\ ${ }^{2}$ Assistant Professor, SRM Institute of Science and Technology, India \\ *Corresponding author: Monisha R, Assistant Professor, SRM College of Physiotherapy, SRM Institute of Science and Technology, Chennai, India
}

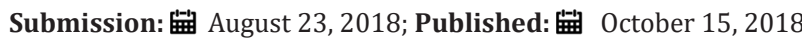

\section{Introduction}

"Clumsy" is often used by the parents and teachers handling the children with Developmental coordination disorder, they were physically awkward and socially not accepted by their age matched peer groups in the society. They were isolated because of their clumsiness and motor difficulty in achieving the daily task of living. These children have neurological soft sign; hypotonia is predominant in muscle groups [1]. They experience deterioration in physical activity as they age, because of the isolation from the society, they experience psychological symptoms like mood and anxiety disorder. Early identification of these children with developmental coordination disorder must be ruled out at the possible ways to avoid further consequences to the society and to the individual [2]. If these children left untreated without proper identification and treatment, they will be involved in malpractices and social negativism has been identified because of this population. When these children were assessed regarding the gait, previous researchers have identified that, they have frequent fall and difficulty in initiating the gait in new environment as they have trouble in crossing up the hurdles in their path [3]. In DCD, Coordination is predominantly below the normal range for the child's age and intelligence (American Psychological Association, 1994). Prevalence of DCD is much higher than wellknown pediatrics conditions such as cerebral palsy and muscular dystrophy. In DCD, poor coordination results in difficulties with motor skills. This negatively affects academic achievement and activities of daily living. If the motor coordination is unresolved, it can persist into adolescence [4]. Although DCD is well recognized by teachers and family members, but the precise characteristics of this condition, particularly it can define as a continuum of cerebral palsy is poorly understood.

Consequences of poor motor coordination are related to functional problems. Alarming number complications have been identified, like problems with self-concept, low achievement, emotional and behavioral difficulties [5]. Motor coordination deficit has been identified in trouble with performing the skilled control of gross motor and fine motor tasks such as writing, dressing and in physical activity. The most frequently performed activities in daily life involves performing sit to stand and walking independently without any assistance. Problems experienced by children with DCD are difficulty in execution of movement and completing it. However voluntary movement like postural adjustments to complex motor activity and postural adjustments to a new modified motor task is poor, which contribute to the poor performance in athletic activity and the efficiency of task performance in everyday activity is poorer [6].

\section{Need for the Study}

Both anticipatory postural adjustments (APA) and reactionary postural adjustments (RPA) are needed in performing an error free activity of daily living. Literature search exist for children with motor coordination difficulties, however the underlying cause behind the development of postural control is more confusing and limited, especially this postural instability in reported in children with developmental coordination disorder in the execution of skilled movement [7].

\section{Methodology}

20 Participants were recruited from primary schools. Details of the study were submitted to the school management, school teachers and parents of all primary schools' children employed in the study, population group selected is in and around Chennai. The study design was approved by Research Committee. After getting written informed consent signed from all participants and their parents before participating in the study. Participants were included in the study, the total age group selected for this study is 8 to 10 -year-old boys 20 participants were asked to perform the baseline evaluation test and they were divided into DCD group ( $\mathrm{N}=8)$ and a non-DCD group $(\mathrm{N}=12)$, The classification of DCD and non-DCD population was in accordance to BOTMP, 
it is a assessment tool in identifying gross motor and fine motor difficulties in children with DCD, but the classification of items into subtest has not been identified and existence of sex difference has been reported. For the postural stability assessment three field test which is gold standardized has been used. For the initiation of these test, children were asked to perform these test with Sport Shoes. Subtest of Bruininks-Oseretsky Test of Motor Proficiency (BOTMP) and sit to stand test has been used in initial evaluation of lower limb strength.

One of the sub-tests employed in BOTMP is standing on one leg (left and right leg) on a balance beam, looking at a target with hands on hips and other leg bent so that it was parallel to the floor. Participants were instructed to maintain this position as long as possible with prior information on the test protocol has been explained to them and the maximum possible score is 10 seconds [8]. The second test used according to BOTMP was walking forward heel-to toe along the balance beam, with hands on hips. Participants were instructed to make six consecutive steps (hitting toes of back foot with heel of front Foot). The number of correct steps was calculated and the maximum score assigned is six. For the field tests employed to all the participants, they were asked to complete three trials of each test and the highest scoring of these trials was taken into account [9]. The multiple sit-to-stand test is performed in children by asking them to stand up from a sitting position, five times consecutively at their normal pace. During the test children were instructed not to lift their feet during sitting. Participants were familiarized with each test by completing one trial. Between three tests there was a recovery period given to participants for five minutes.

\section{Data Collection}

Table 1 and Figure 1

Table 1: Difference between the standardized field test performance in children with and without DCD.

\begin{tabular}{|c|c|c|c|c|c|c|c|c|}
\hline & & \multirow[t]{2}{*}{ Mean } & \multirow{2}{*}{$\begin{array}{l}\text { Std. De- } \\
\text { viation }\end{array}$} & \multirow[t]{2}{*}{ Std. Error Mean } & \multicolumn{2}{|c|}{$\begin{array}{l}\text { 95\% Confidence Interval of the } \\
\text { Difference }\end{array}$} & \multirow[t]{2}{*}{$\mathbf{t}$} & \multirow[t]{2}{*}{ Sig. (2-tailed } \\
\hline & & & & & Lower & Upper & & \\
\hline $\begin{array}{c}\text { Pair } \\
1\end{array}$ & $\begin{array}{c}\text { Child DCD unilateral } \\
\text { dominant leg child non } \\
\text { DCD unilateral dominant } \\
\text { leg }\end{array}$ & -6.625 & 1.92261 & 0.67975 & -8.23234 & -5.01766 & -9.746 & 0 \\
\hline $\begin{array}{l}\text { Pair } \\
2\end{array}$ & $\begin{array}{l}\text { Child DCD unilateral non- } \\
\text { dominant leg-child non } \\
\text { DCD unilateral nondomi- } \\
\text { nant leg }\end{array}$ & -3.625 & 0.51755 & 0.18298 & -4.05768 & -3.19232 & -19.811 & 0 \\
\hline $\begin{array}{l}\text { Pair } \\
3\end{array}$ & $\begin{array}{l}\text { Child DCD heel to toe } \\
\text { walk-child non DCD heel } \\
\text { to toe walk }\end{array}$ & 1.375 & 1.18773 & 0.41993 & 0.38203 & 2.36797 & 3.274 & 0.014 \\
\hline $\begin{array}{l}\text { Pair } \\
4\end{array}$ & $\begin{array}{l}\text { Child DCD sit to stand- } \\
\text { child non DCD sit to stand }\end{array}$ & 10.375 & 3.85218 & 1.36195 & 7.1545 & 13.5955 & 7.618 & 0 \\
\hline
\end{tabular}

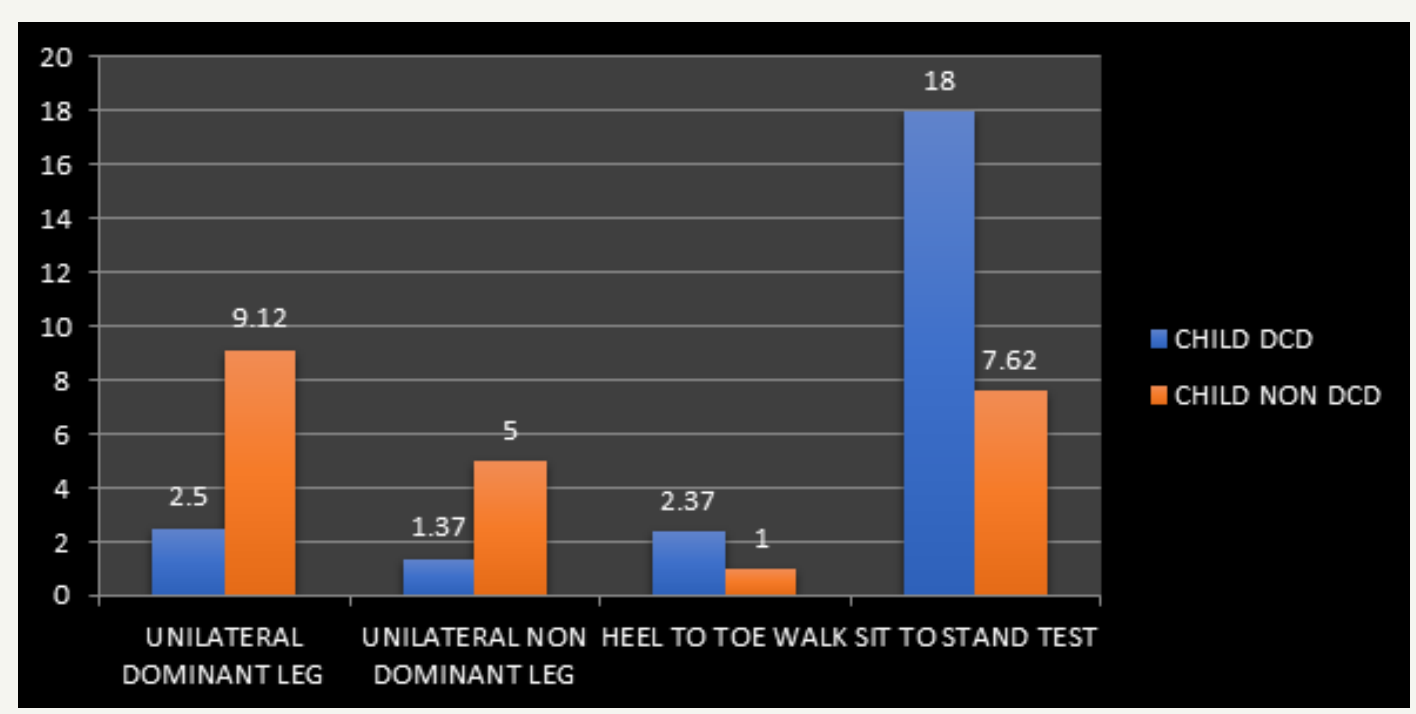

Figure 1: Children with dcd and non-dcd in field test performance. 


\section{Discussion}

The purpose of this study was to assess the postural skills in children with DCD versus normal age matched peer groups. Simple field test that assess the postural stability, that is needed to be achieved in everyday life's task were used as an outcome assessor in this study population. Sitting to standing is the common activity of daily living that is needed to achieve the functional tasks such as Rising from a seated to a standing position. It has been reported that children with DCD were having poor coordination of lifting the body from sitting to standing; they always prefer not to stand as often [10]. It has been stated that, these children took long time to perform sit to stand activity and they had poor postural control when standing up from sitting position, they have sway and fall into the chair with trunk inclining backwards and lower limb lifts off from the floor. They were instructed to perform multiple sit to stand test, but these children need repeated instructions to do the same. In other field test they shows poor performance and sway has been reported. Walking is the most common physical activity performed by all children. Previous Researchers have highlighted that children with DCD have difficulty walking, when exposed to a new environment and left with hurdles in the waking path they experiences fall and postural sway.

Tandem walking and retro walking were demonstrated to the children with developmental coordination disorder, after a trial walk, these children were instructed to walk backwards. In tandem walking they have been asked to walk in a bright white color line, by keeping their heel close together to the fingers of the foot, as they initiate gait, they found this field test most difficult to continue and they reported fall and loss of coordination is persistent in these children. Walking heel-to-toe on a narrow base of support is not difficult in children with normal developing peer groups. Although unexpected, differences in tandem walking performances were more apparent in children with and without DCD.

\section{Conclusion}

DCD is a condition characterized by significant functional Difficulty in motor skill. children with DCD reported significantly longer to perceive the visual signals and to coordinate the gait initiation by following the instructions to perform the field test
When these children were assigned goal-directed movement postural instability has been reported. Thus, this study concludes by provided new knowledge regarding the persistence of postural instability in children with DCD

\section{Further Recommendations}

a. Further research is needed to analyze the postural control and postural muscles in detail in larger sample size

Poor postural muscle function is a hypothesized contributor to this problem. This Hypothesis needs evaluation in the future.

\section{References}

1. Ganapathy U, Saritha S (2011) A study of prevalence of developmental coordination disorder (DCD) at Kattankulathur, Chennai, Indian Journal of Physiotherapy and occupational therapy 5(1): 63-65.

2. Ganapathy U (2018) The prevalence of developmental coordination disorder at Kattupakkam, Tamilnadu. IOSR Journal of Pharmacy 8(2): 49-52.

3. Zattara M, Bouisset S (1988) Posturo-kinetic organisation during the early phase of upper limb movement. J Neurol Neurosurg Psychiatry 51(7): 956-965.

4. Williams H, Fisher J, Tritschler K (1983) Descriptive analysis of static postural control in 4, 6 and 8 year old normal and motorically awkward children. Am J Phys Med 62(1): 12-26.

5. Van Dellen T, Geuze R (1988) Motor response processing in clumsy children. J Child Psychol Psychiatry 29(4): 489-500.

6. Shumway-Cook A, Woollacott MH (1985) The growth of stability: postural control from a developmental perspective. J Mot Behav 17(2): 131147.

7. Pal_tsev Y, El_ner A (1967) Preparatory and compensatory period during voluntary movement in patients with involvement of the brain at different locations. Pflugers Archives 12: 161-168.

8. Cairney J, Hay JA, Faught BE, Wade TJ, Corna L, et al. (2005) Developmental coordination disorder, generalized self-efficacy toward physical activity, and participation in organized and free play activities. J Pediatr 147(4): 515-520.

9. Mcllroy WE, Maki BE (1997) Preferred placement of the feet during quiet stance: development of a standardized foot placement for balance testing. Clin Biomech 12(1): 66-70.

10. Sibella F, Galli M, Romei M, Montesano A, Crivellini M (2003) Biomechanical analysis of sit-to-stand movement in normal and obese subjects. Clin Biomech 18(8): 745-750.
Creative Commons Attribution 4.0 International License

For possible submissions Click Here

\section{Submit Article}

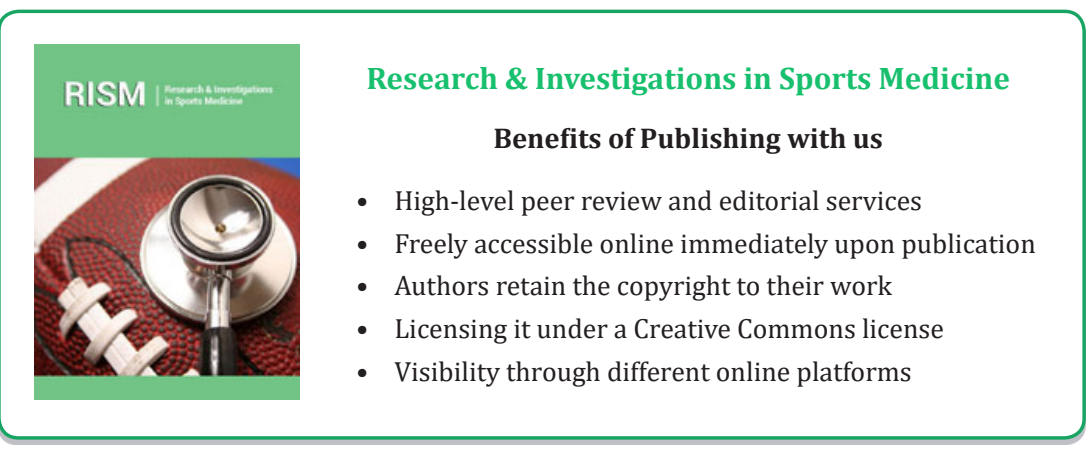

